\title{
Data from the European registry for patients with McArdle disease and other muscle glycogenoses (EUROMAC)
}

Renata S. Scalco ${ }^{1}$, Alejandro Lucia ${ }^{2,3}$, Alfredo Santalla ${ }^{3,4}$, Andrea Martinuzzi $^{5}$, Marinela Vavla ${ }^{5}$, Gianluigi Reni ${ }^{5}$, Antonio Toscano ${ }^{6}$, Olimpia Musumeci ${ }^{6}$, Nicol C. Voermans ${ }^{7}$, Carlyn V. Kouwenberg ${ }^{7}$, Pascal Laforêt ${ }^{8}$, Beatriz San-Millán ${ }^{9,10}$, Irene Vieitez ${ }^{10}$, Gabriele Siciliano ${ }^{11}$, Enrico Kühnle ${ }^{12}$, Rebeca Trost $^{12}$, Sabrina Sacconi ${ }^{13}$, Mads G. Stemmerik ${ }^{14}$, Hacer Durmus ${ }^{15}$, Biruta Kierdaszuk ${ }^{16}$, Andrew Wakelin ${ }^{17}$, Antoni L. Andreu ${ }^{18}$, Tomàs Pinós ${ }^{18}$, Ramon Marti ${ }^{18}$, Ros Quinlivan ${ }^{1}$ and John Vissing ${ }^{14^{*}}$ (1) on behalf of EUROMAC Consortium

\begin{abstract}
Background: The European registry for patients with McArdle disease and other muscle glycogenoses (EUROMAC) was launched to register rare muscle glycogenoses in Europe, to facilitate recruitment for research trials and to learn about the phenotypes and disseminate knowledge about the diseases through workshops and websites. A network of twenty full and collaborating partners from eight European countries and the US contributed data on rare muscle glycogenosis in the EUROMAC registry. After approximately 3 years of data collection, the data in the registry was analysed.
\end{abstract}

Results: Of 282 patients with confirmed diagnoses of muscle glycogenosis, 269 had McArdle disease. New phenotypic features of McArdle disease were suggested, including a higher frequency (51.4\%) of fixed weakness than reported before, normal CK values in a minority of patients (6.8\%), ptosis in 8 patients, body mass index above background population and number of comorbidities with a higher frequency than in the background population (hypothyroidism, coronary heart disease).

Conclusions: The EUROMAC project and registry have provided insight into new phenotypic features of McArdle disease and the variety of co-comorbidities affecting people with McArdle disease. This should lead to better management of these disorders in the future, including controlling weight, and preventive screening for thyroid and coronary artery diseases, as well as physical examination with attention on occurrence of ptosis and fixed muscle weakness. Normal serum creatine kinase in a minority of patients stresses the need to not discard a diagnosis of McArdle disease even though creatine kinase is normal and episodes of myoglobinuria are absent.

Keywords: Myopathy, Rare diseases, International registry, McArdle disease, Metabolic diseases, Glycogen storage disease

*Correspondence: john.vissing@regionh.dk

${ }^{14}$ Copenhagen Neuromuscular Center, Section 6921, Rigshospitalet, University of Copenhagen, 2100 Copenhagen, Denmark

Full list of author information is available at the end of the article

\section{Introduction}

Understanding rare conditions is usually based on case series or small observational studies. Thus, gaining knowledge about disease phenotypes and development is challenging. For instance, lack of natural history data negatively impacts on identification of clinically important endpoints to be used in clinical trials [1]. Other 
challenges include delayed diagnosis, poor subject availability for recruitment into clinical trials and a lack of standardised care [1-3]. As a result, the development of new pharmacological treatments for such conditions is delayed and compromised $[1,2]$.

To overcome these limitations, there are increasing incentives to develop international registries. Registries are considered key instruments for developing research in the field of rare conditions, including glycogen storage diseases (GSDs) [4]. The EUROMAC project was funded by the European Union aiming to establish a network of clinical centres to develop the first European Registry for patients with McArdle Disease and very rare related muscle glycogenolytic disorders presenting with activity/ exercise intolerance as the key symptom $[5,6]$. The project was designed and built as described in the accompanying paper to this report [7], to raise awareness of diagnostic accuracy of muscle GSDs, improve the care, and collect important clinical and epidemiological data that can better describe the phenotypes and indicate endpoints for use in future clinical trials.

This paper describes the data collected in the EUROMAC registry for patients with McArdle disease.

\section{Methods}

The registry was designed under the guidance and consensus of EUROMAC members at specific meetings during the first months of the EUROMAC project. EUROMAC members were twenty full and collaborating partners from eight European countries (Denmark, France, Germany, Greece, Italy, Spain, Turkey and United Kingdom) and USA. The Netherlands and Poland joined the project later and contributed patients to the registry. The registry obtained the approval of all local Institutional review Boards for patient entry at the registry website (www.registryeuromac.eu). The project was divided into eight work packages (WP) to develop the registry (see Table 2 in accompanying paper) [7]. The technical setup and data security for the registry are detailed in the accompanying paper [7].

After review by people affected by GSDs and by a patient representative (WP2 - AGSD-UK) to ensure clarity [8], the participant information sheet and consent form were translated into languages of the participating countries and adapted to follow local regulations. All patients consented in writing before inclusion in the registry.

Any doctor working at a European institution was able to register on the EUROMAC platform and enter patient data. Inclusion criteria were patients with a diagnosis of one of the 14 known muscle GSDs either verified by the presence of two pathogenic mutations in the relevant genes (one pathogenic mutation for phosphorylase $b$ kinase and phosphoglycerate kinase deficiencies as they are X-linked) or for McArdle disease and phosphofructokinase deficiency, lack of enzymatic staining on muscle biopsy. Patients with Pompe disease were excluded as there is a well-established registry for this disease already (https://clinicaltrials.gov/ct2/show/NCT0023140 $0)$. Following informed consent from the participant, data were uploaded onto a safe, encrypted web-based registry. Recruited participants were able to log in, review their own information and complete selected sections with their personal experiences. None of the recruited participants or participating doctors were allowed to see data from other patients. Data entry items are shown in Table 3 of the accompanying paper [7]. Muscle strength was assessed by manual muscle testing in patients older than 18 years $(n=247)$ by a trained neuromuscular specialist. Data was only entered once, except if missing data was uploaded later. Data was based on clinical status and medical history at data entry.

\section{Results \\ Patient registry}

The first patient was entered into the registry in February 2015. Until March 2018, 313 patients from 10 countries were added to the registry. Thirty-one patients were excluded from data analysis due to incomplete data entry related to diagnosis (i.e., missing muscle biopsy and/or missing genetic data). Thus, 282 participants were included in data analysis (Fig. 1). In this cohort, the most frequent GSD diagnosis was McArdle disease $(\mathrm{n}=269 ; 95.4 \%)$. Other conditions included GSDIIIa $(\mathrm{n}=2)$, GSDVII $(\mathrm{n}=5)$, GSDIX $(\mathrm{n}=2)$, GSDX $(\mathrm{n}=1)$,

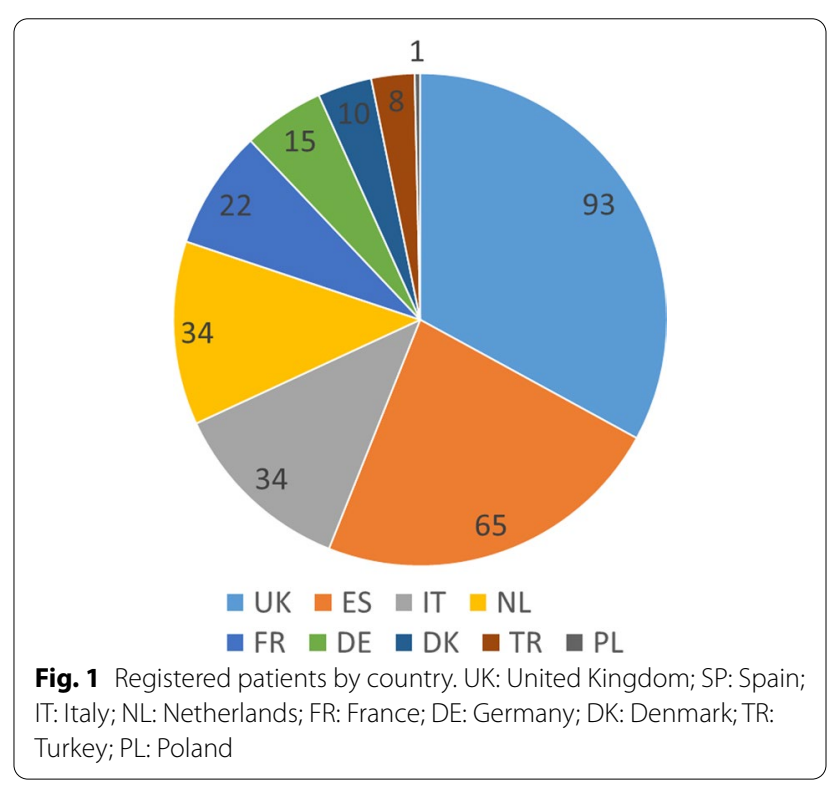


$\operatorname{GSDXIV}(\mathrm{n}=1)$, and GSDXV $(\mathrm{n}=2)$. Detailed information on the 13 patients with rarer types of GSD are omitted as the sample is too small for data analysis. Following a EUROMAC teaching course held in Warsaw, the first Polish patient was diagnosed with McArdle disease, and entered into the registry [9].

\section{McArdle disease: GSDV ( $n=269)$ \\ Patient demographics}

Age ranged from 8-82 years, with a median age of 46 years. Fifty-three percent were males $(n=142)$ and $47 \%$ females $(n=127)$. Completeness of data entry for different items is shown in Table 1.

\section{Diagnosis}

The median age at diagnosis was 30 years (range: 5-79 years), with no difference between men and women. Table 2 illustrates the use of the diagnostic tests (genetic testing, muscle biopsy). In total, $90.0 \%$ of patients had a genetic test performed at some stage of the diagnostic investigation.

Of all McArdle patients with two pathogenic variants identified ( $\mathrm{n}=242)$, the allele frequency for the $\mathrm{c} .148 \mathrm{C}>\mathrm{T}$ (p.R50X) variant was (62.4\%) occurring as either

Table 1 Incomplete data related to patients with McArdle disease (GSDV)

\begin{tabular}{lcl}
\hline & $\begin{array}{l}\text { Missing } \\
\text { data (n) }\end{array}$ & $\begin{array}{l}\text { Total number of patients } \\
\text { considered for the outcome } \\
\text { analysis (n) }\end{array}$ \\
\hline Current age & 1 & 268 \\
Age at diagnosis & 3 & 266 \\
BMl & 44 & $203^{\mathrm{a}}$ \\
Second wind & 41 & 228 \\
CK (baseline, all) & 93 & 176 \\
CK (baseline/ weakness) & 39 & $88^{\mathrm{b}}$ \\
Analgesia use & 91 & 178 \\
Comorbidities & 28 & 241
\end{tabular}

a Only patients aged 18 years or older were included in the data analysis for body mass index (BMI)

${ }^{b}$ Creatine kinase (CK) levels are shown for all patients in whom it was measured at baseline and the subset of patients who were affected by muscle weakness homozygous (108) or compound heterozygous (86). The allele frequency for the c.613G >A (p.G205S) variant was 6.4\% (homozygous in 5 and compound heterozygous in 21), and the allele frequency for the c.2262delA was $4.3 \%$ \% (homozygous in 4 and compound heterozygous in 13) (Table 3). All other alleles occurred at a frequency below $2 \%$. Only five other pathogenic variants were found in 5-10 McArdle patients, and the other pathogenic variants were mostly private. Sixteen novel pathogenic variants, not previously reported in the Human Gene Mutation Database, were identified (Table 3).

\section{Body mass index (BMI)}

BMI was analysed in people older than 18 years $(n=203)$. The median BMI in this cohort was $25.9 \mathrm{~kg} / \mathrm{m}^{2}$ (range: $16.6-52.8 \mathrm{~kg} / \mathrm{m}^{2}$ ). Abnormal BMI was observed in $62.6 \%$ (Fig. 2).

\section{McArdle-related signs and symptoms}

Most patients identified spontaneous second wind (82\%, $\mathrm{n}=187$ ), while 41 patients $(18 \%)$ had not previously recognised the phenomenon. Baseline serum creatine kinase (CK) levels varied from 99 to 32,394 IU/L (median: 1,475 IU/L). Twelve McArdle patients (6.8\%) had baseline CK below the normal upper reference level of $240 \mathrm{IU} / \mathrm{L}$. Ten patients (5.7\%) had CK levels higher than 10,000 IU/L. Previous episodes of myoglobinuria were reported by $61.7 \%$ of patients $(n=166) .71 .1 \%$ of these patients had recurrent rhabdomyolysis. No previous episode of myoglobinuria was reported by $39.4 \%$ of patients $(\mathrm{n}=106)$.

Muscle weakness was observed in 127 (51.4\%). The median age of those patients was 47 years. Weakness affected men (52\%) and women (48\%) equally. Weakness preferentially affected upper body and trunk muscles as shown in Table 4. The median age of patients not affected by muscle weakness was also 47 years.

There were no significant differences in CK levels in patients with weakness compared with those with no weakness (Table 5) although five of the patients with weakness had CK lower than $240 \mathrm{IU} / \mathrm{L}$. Eight patients (3.2\%) had ptosis (median age: 54.5 years) and in one of

Table 2 Diagnostic investigations and age at diagnosis

\begin{tabular}{llll}
\hline Diagnostic test & $\mathbf{n}(\%)$ & $\begin{array}{l}\text { Age at diagnosis } \\
\text { median age (age range) }\end{array}$ & $\begin{array}{l}\text { Current age } \\
\text { median age (age range) }\end{array}$ \\
\hline Genetic test (only) & $101(37.5 \%)$ & 27.5 years (8-79) & 43 years (10-80) \\
Muscle biopsy (only) & $27(10.0 \%)$ & 30 years (12-58) & 50 years (16-75) \\
Muscle biopsy+ Genetic test & $141(52.4 \%)$ & 32 years (5-76) & 46 years (8-82) \\
Total & 269 & & \\
\hline
\end{tabular}


Table 3 List of pathogenic variants assessed in 242 patients with McArdle disease

\begin{tabular}{|c|c|c|}
\hline Mutation & Heterozygous & Homozygous \\
\hline C. $148 C>T$ & 86 & 108 \\
\hline c. $613 \mathrm{G}>\mathrm{A}$ & 21 & 5 \\
\hline c.2262delA & 13 & 4 \\
\hline C. $1190 \mathrm{~T}>\mathrm{C}$ & 8 & 0 \\
\hline $\mathrm{C} .808 \mathrm{C}>\mathrm{T}$ & 6 & 0 \\
\hline$c .1 A>G$ & 1 & 5 \\
\hline c. $2392 \mathrm{~T}>\mathrm{C}$ & 7 & 0 \\
\hline c. $1466 C>G$ & 4 & 0 \\
\hline C. $1282 C>T$ & 3 & 0 \\
\hline c.13_14delCT & 3 & 0 \\
\hline c. $1129 A>T$ & 2 & 0 \\
\hline c.1162_1169delTGGCCGGTinsA & 2 & 0 \\
\hline c. $1366 G>A$ & 2 & 0 \\
\hline c. $1468+1 G>A$ & 2 & 0 \\
\hline C. $1760 T>C$ & 2 & 0 \\
\hline c. $1769 \mathrm{G}>\mathrm{A}$ & 1 & 1 \\
\hline c. $1827 G>A$ & 2 & 0 \\
\hline c. $2056 \mathrm{G}>\mathrm{A}$ & 2 & 0 \\
\hline c.2113_2114delGG & 2 & 0 \\
\hline c.2128_2130delTTC & 0 & 2 \\
\hline$C .2143 C>T$ & 2 & 0 \\
\hline c.2385_2386delAA & 2 & 0 \\
\hline$c .415 C>T$ & 1 & 1 \\
\hline$c .481 C>T$ & 2 & 0 \\
\hline c. $661-601 \mathrm{G}>\mathrm{A}$ & 1 & 1 \\
\hline c. $1345 G>A$ & 2 & 0 \\
\hline c. $1768+1 \mathrm{G}>\mathrm{A}$ & 2 & 0 \\
\hline c.2259_2261delA & 1 & 1 \\
\hline c.1275-1276insG & 2 & 0 \\
\hline$c .2177+1 G>A$ & 2 & 0 \\
\hline c.773-2A>T & 1 & 0 \\
\hline C. $1463 C>T$ & 1 & 0 \\
\hline c. $1723 A>G$ & 0 & 1 \\
\hline c. $1730 A>G$ & 1 & 0 \\
\hline p.R387Afs $* 37^{\theta}$ & 1 & 0 \\
\hline c. $1805 \mathrm{G}>\mathrm{A}$ & 1 & 0 \\
\hline C. $1948 C>T$ & 1 & 0 \\
\hline c.2075_2076delCCinsAAA & 1 & 0 \\
\hline c. $2083 G>A$ & 1 & 0 \\
\hline$c .2441 G>A$ & 1 & 0 \\
\hline c.244-3_244-2delCA & 1 & 0 \\
\hline c. $255 C>A$ & 1 & 0 \\
\hline c.347T>C & 1 & 0 \\
\hline$c .458 \mathrm{~T}>\mathrm{G}$ & 1 & 0 \\
\hline c. $580 C>T$ & 1 & 0 \\
\hline c.715_717delGTC & 1 & 0 \\
\hline c.1093-1G>T & 1 & 0 \\
\hline c. $1239+1$ & 1 & 0 \\
\hline c.397G $>A$ & 1 & 0 \\
\hline
\end{tabular}

Table 3 (continued)

\begin{tabular}{|c|c|c|}
\hline Mutation & Heterozygous & Homozygous \\
\hline c. $1475 \mathrm{G}>\mathrm{A}$ & 1 & 0 \\
\hline c. $1094 C>A$ & 1 & 0 \\
\hline c. $1093-2 A>G$ & 1 & 0 \\
\hline c.1275delG & 1 & 0 \\
\hline$c .507 G>T$ & 0 & 1 \\
\hline c.558delC & 1 & 0 \\
\hline c. $345+2 T>A$ & 1 & 0 \\
\hline c.597-598delT & 1 & 0 \\
\hline p.V25fs51 $1 X^{\theta}$ & 0 & 1 \\
\hline c.1477delC & 1 & 0 \\
\hline c.227delG & 1 & 0 \\
\hline c. $2178+1 G>A$ & 1 & 0 \\
\hline C. $1478 T>C$ & 0 & 1 \\
\hline C. $1700 A>C$ & 0 & 1 \\
\hline c. $1700 A>G$ & 1 & 0 \\
\hline
\end{tabular}

Pathogenic variants are listed according to their frequency. Numbers in columns below the headings "heterozygous" and "homozygous" show number of persons carrying the pathogenic variant in a compound heterozygous or homozygous state. Pathogenic variants that are in italic are novel pathogenic variants not present in Human Gene Mutation Database. $\theta$ signifies frameshift pathogenic variants where the nucleotide change is unavailable

them, ptosis was the only evidence of muscle weakness. Relationship between genotype and laboratory/clinical findings can be viewed in Additional file 1: Table S1.

Forty-two patients (23.6\%) used analgesic medication to manage pain symptoms, which included: paracetamol $(n=19)$, nonsteroidal anti-inflammatory drugs $(n=17)$, opioids $(\mathrm{n}=14)$, central analgesic $(\mathrm{n}=5)$ and steroids $(\mathrm{n}=1)$.

\section{Cardiorespiratory fitness (peak oxygen uptake $\left[\mathrm{VO}_{2 \text { peak }}\right]$ )}

A cycle ergometry exercise test was performed in 71 patients in Spain $(n=41)$, Italy $(n=14)$, United Kingdom $(n=9)$ and Denmark $(n=7)$; one exercise test was excluded from data analysis as the cycle test was interrupted prematurely. The median $\mathrm{VO}_{2 \text { peak }}$ was $18.5 \mathrm{ml} /$ $\mathrm{kg} / \mathrm{min}(7-33)$. This value is a little less than half that expected in matched healthy people. The lowest result was seen in a 48-year-old woman with fixed muscle weakness.

\section{Comorbidities}

In this cohort, 80 people (33.2\%) did not have any comorbidity (median age: 34 years). Recorded comorbidities are shown in Table 6. Median age of patients with comorbidities was 50 years (12-82). Hypothyroidism affected men $(\mathrm{n}=7)$ and women $(\mathrm{n}=7)$ equally (age range at data entry: 17 - 77 years; median age: 59.5 years; mean age: 52.5 years). The two thyroid gland tumors reported were a benign adenoma and a malignant carcinoma. 


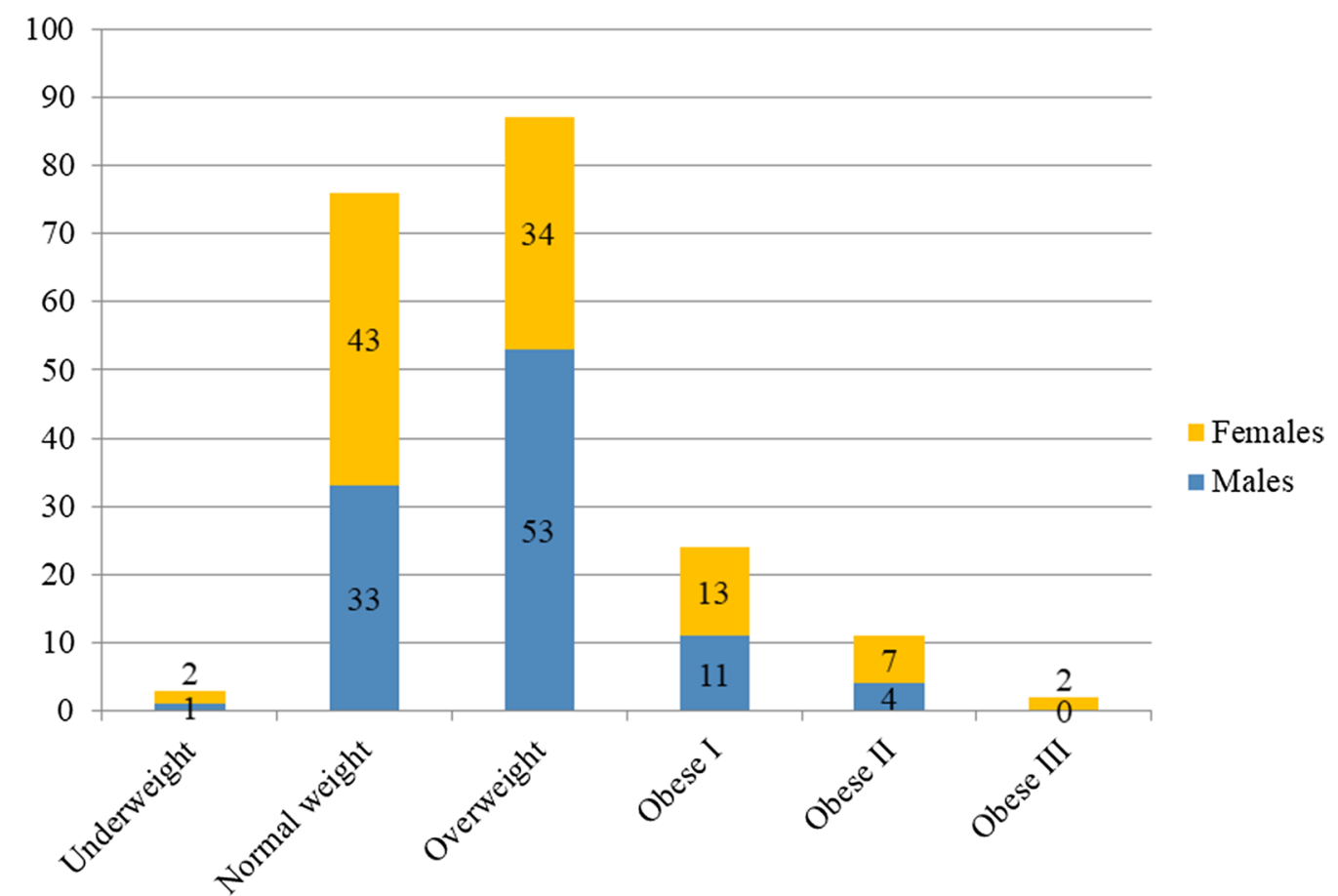

Fig. 2 Body mass index (BMI) in 203 adult patients with McArdle disease (GSDV). Underweight:<18.5; Normal weight: 18.5-24.9; Overweight: 25.0-29.9; Obese I: 30.0-34.9; Obese II: 35.0-39.9; Obese III: $\geq 40 \mathrm{~kg} / \mathrm{m}^{2}$

Table 4 Muscle weakness in 127 adults with McArdle disease

\begin{tabular}{lc}
\hline Affected muscles & $\mathbf{n}$ \\
\hline Upper limbs/trunk & 74 \\
Lower limbs & 21 \\
Upper and lower limbs + trunk & 31 \\
Ptosis & 8 \\
Mastication muscles & 1 \\
\hline
\end{tabular}

The total number of patients in the table exceeds 127 as 7 of 8 patients with ptosis and the patient with affection of the masticatory muscles also had limb or truncal weakness. Weakness in upper and lower limbs and trunk, was defined as weakness of one or more muscle groups in each region

Table 5 Serum creatine kinase (CK) levels in patients according to muscle weakness

\begin{tabular}{lll}
\hline & Median CK (IU/L) & Range (IU/L) \\
\hline Weakness & 1519.5 & $137-32,394$ \\
No weakness & 1271 & $99-25,459$ \\
\hline
\end{tabular}

Ophthalmological conditions included retinal problems $(n=3)$, cataract $(n=1)$ and uveitis $(n=1)$. Retinal problems included macular degeneration, retinoschisis and a history of three retinal detachments, and retinal dystrophy. Of the 19 patients with a history of acute kidney failure, 17 had a positive history for a previous episode of myoglobinuria. Thyroid problems $(n=20)$ were the most frequent among the endocrine diseases, with prevalence higher than diabetes $(n=15)$.

\section{Discussion}

Besides a specific international Pompe disease registry, EUROMAC is the only international registry of muscle glycogenoses reported to date that serves as a pan-European reference to register people with rare muscle GSDs to improve knowledge and promote research in these conditions. Besides unravelling phenotype characteristics of McArdle disease as discussed below, the EUROMAC project also played a key role in education and training in several European countries. The registry has also contributed to the promotion and/or implementation of international clinical trials [10-21], illustrating its positive role in promoting translational research.

The most common muscle GSD represented in this European cohort was McArdle disease.

Although data on age at onset of symptoms were not recorded in the registry, because of a presumed high level of recall bias, there seems to be a considerable delay in diagnosing the GSDs, which highlights the need for better awareness of these conditions. So, besides creating the EUROMAC registry, it emphasizes the importance of the EUROMAC education and dissemination activities 
Table 6 Comorbidities reported

\begin{tabular}{|c|c|c|c|}
\hline Comorbidities & $\mathrm{N}$ & $\begin{array}{l}\text { Frequency in this } \\
\text { Cohort }(n=241) \\
(\%)\end{array}$ & $\begin{array}{l}\text { Median age } \\
\text { (range) Years }\end{array}$ \\
\hline Hypertension & 41 & 17 & $57(39-82)$ \\
\hline Endocrine disease (Total) & 38 & 15.7 & $56(17-77)$ \\
\hline Diabetes & 15 & & \\
\hline Hypothyroidism & 14 & & \\
\hline Thyrotoxicosis & 2 & & \\
\hline Thyroid tumour & 2 & & \\
\hline Hyperthyroidism & 2 & & \\
\hline Other endocrine problems & 3 & & \\
\hline $\begin{array}{l}\text { Musculoskeletal/rheumatic } \\
\text { disease }\end{array}$ & 31 & 12.9 & $52(15-82)$ \\
\hline Coronary artery disease & 20 & 8.3 & $62(42-80)$ \\
\hline Other cardiovascular disease & 10 & 4.1 & $54.5(35-80)$ \\
\hline Hyperuricemia/gout & 28 & 11.6 & $60.5(24-80)$ \\
\hline $\begin{array}{l}\text { Gastroenterological dis- } \\
\text { ease (Total) }\end{array}$ & 27 & 11.2 & $52(12-77)$ \\
\hline Gall bladder problems & 6 & & \\
\hline $\begin{array}{l}\text { Hiatus hernia and/or acid } \\
\text { reflux }\end{array}$ & 4 & & \\
\hline Crohn's disease & 3 & & \\
\hline Irritable bowel syndrome & 3 & & \\
\hline Coeliac disease & 3 & & \\
\hline Diverticulitis or polyposis & 2 & & \\
\hline Constipation & 1 & & \\
\hline Gastritis & 1 & & \\
\hline Liver disease $^{\mathrm{a}}$ & $4^{a}$ & & \\
\hline Pancreatitis $^{\mathrm{a}}$ & $2^{a}$ & & \\
\hline Neurological disease & 24 & 10 & $51.5(13-81)$ \\
\hline Respiratory disease & 23 & 9.5 & $51(12-75)$ \\
\hline Acute renal failure & 19 & 7.9 & $53(33-76)$ \\
\hline Chronic renal failure & 3 & 1.2 & $44(17-49)$ \\
\hline Dyslipidaemia & 21 & 8.7 & $57(24-82)$ \\
\hline Mental disorder (Total) & 16 & 6.6 & $49(13-75)$ \\
\hline Depression & 9 & & \\
\hline Anxiety & 4 & & \\
\hline Bipolar disorder & 1 & & \\
\hline Schizophrenia & 1 & & \\
\hline $\begin{array}{l}\text { Post-traumatic stress } \\
\text { disorder }\end{array}$ & 1 & & \\
\hline Cancer & 11 & 4.6 & $55(33-82)$ \\
\hline Anaemia/hyperbilirubinemia & 9 & 3.7 & $39(26-82)$ \\
\hline Ophthalmological disease & 5 & 2.1 & $67(60-73)$ \\
\hline Others & 54 & 22.4 & $53(19-80)$ \\
\hline
\end{tabular}

${ }^{a}$ Two patients had two gastroenterological diseases: Thus, the sum in the table is higher than the total number of patients affected by a gastroenterological disease

[22-25]. The increased use of genetic diagnostic testing reflects the shift towards a molecular genetic approach across all participating countries, which likely will facilitate more timely diagnosis of muscle GSDs. The registry confirmed the high prevalence of the two common variants, c.148C > T (p.R50X) and c.613G>A (p.G205S) in the European population of McArdle patients, and added 16 novel pathogenic variants to the list of approximately 150 known, pathogenic PYGM variants.

As previously reported, the serum CK levels were high in most patients with McArdle disease, however, it was surprising to find that $6.8 \%$ of patients had CK levels within normal range. All patients with normal CK levels had a confirmed genetic diagnosis and had typical symptoms of McArdle disease, such as exercise-induced pain and contractures and exercise intolerance, which led to diagnostic testing for the disease. Four of the patients with normal CK levels had a history of myoglobinuria.

Normal CK levels were also seen in more severely affected people, including those with fixed muscle weakness. An important message therefore is that a normal $\mathrm{CK}$ and a negative history for myoglobinuria do not exclude a diagnosis of McArdle disease.

There was a higher frequency of fixed muscle weakness reported in this cohort compared with previous studies of patients of the same age $[23,24,26]$, suggesting that this condition may have been under-recognized in the past. A major new finding from our registry data was the presence of ptosis in a small proportion of patients with McArdle disease, suggesting that this can also be a feature of this glycogenosis, as it has also been noticed in patients with GSDII (Pompe disease) [27, 28].

We also found that BMI was higher than normal in almost two thirds of patients, likely reflecting a sedentary lifestyle related to the poor exercise tolerance and muscle pain on exertion. This is relevant for these diseases as overweight and general low physical activity level promotes low insulin sensitivity, diabetes and metabolic syndrome, factors that may exacerbate the condition. Coronary artery disease was the most common heart disorder. Surprisingly, thyroid disease was the most common endocrine disorder, with a higher frequency than diabetes. The prevalence of hypothyroidism is $1-2 \%$ in iodine-sufficient parts of the world [29], which is lower than the prevalence reported in the present study (5.8\%). This is the first time an increased frequency of thyroid problems was reported in people affected by McArdle disease, but the reason for this warrants further study. The authors recommend performing regular TSH surveillance for patients at their follow-up visits.

Three patients had chronic renal failure, indicating that recurrent rhabdomyolysis, which is common in this population, rarely results in irreversible kidney damage. Three patients had retinal problems. Even though a recently published case series has identified four more McArdle patients with retinal disease [30], it is still 
uncertain whether this is part of the disease. The possibility of associated retinal disease should be explored further, and therefore a retinal exam should be performed at least once in patients.

Limitations of this study include the collection of retrospective data and the presence of missing data. Further efforts to maintain a prospective registry for rare diseases may help gaining further understanding on the natural history of rare conditions such as McArdle disease.

\section{Conclusions}

The EUROMAC project and international registry have significantly raised awareness of McArdle disease, and should inspire opinion leaders in other fields to develop similar patient registries.

The analysis of the registry data has given insight into new phenotypic features of McArdle disease and the variety of co-comorbidities affecting people with McArdle disease, which should lead to strategies reducing and managing these in the future, including controlling weight, and preventive screening for thyroid and coronary artery diseases. The data of the registry suggest that physical examination should focus more on occurrence of ptosis and fixed muscle weakness, which may be overlooked, and stresses the need not to discard a diagnosis of McArdle disease even though CK is normal and episodes of myoglobinuria are absent.

\section{Supplementary information}

Supplementary information accompanies this paper at https://doi. org/10.1186/s13023-020-01562-x.

Additional file 1. Genetic variants according to clinical features.

\section{Abbreviations}

AGSD-UK: Association for Glycogen Storage Disease (UK); CK: Creatine kinase; GSD: Glycogen storage disease; GSD-V: Glycogen storage disease type V; $\mathrm{VO}_{\text {2peak }}$ : Peak oxygen uptake; NSAID: Non-steroidal anti-inflammatory drugs; WP: Work package.

\section{Acknowledgements}

EUROMAC was supported by several patients' associations and large networks of patient registries, such as the Association for Glycogen Storage Disease (https://agsd.org.uk/) and the EPIRARE Group on Rare Disease Registries (https ://www.eurordis.org/content/epirare). The European Neuromuscular Centre (https://www.enmc.org/) also supported the project by contributing to the organization and funding of a dedicated workshop.

EUROMAC Consortium: Antoni L. Andreu, Ramon Martí, Tomàs Pinós, Noemi Baruch, Francisco J. Ortega, Miguel A. Martín, Carmen Navarro, Beatriz San Millán, Irene Vieitez, Andrea Martinuzzi, Monica Castelli, Federica Zucchi, Claudio Bruno, Antonio Toscano, Olimpia Musumeci, Pascal Laforêt, Sabrina Sacconi, Ros Quinlivan, Renata Scalco, Andrew Wakelin, Georgios Hadjgeorgiou, Elias Zintzaras, John Vissing, Matthias Vorgerd, Enrico Zülow, Ronald Haller, Piraye Oflazer, Hacer Durmus, Jean Pouget, Alejandro Lucia, Alfredo Santalla.

\section{Authors' contributions}

All authors: data collection, manuscript review for intellectual content. Additional contributions for individual authors are; RSS and JV: data analysis and interpretation and drafting the manuscript. ALA: coordination of the EUROMAC proposal and creation of the consortium. RM and TP: coordination of the EUROMAC project and registering activity. All authors read and approved the final manuscript.

\section{Funding}

EUROMAC was funded by the European Commission's Consumers, Health Agriculture and Food Executive Agency (CHAFEA, Grant 2012-12-14 to the EUROMAC consortium), and by the Spanish Instituto de Salud Carlos III, co-funded by the European Regional Development Funds, ERDF (Grants PI16/01492, PI19/01313 and CIBERER-ACCI 2016-03, to TP).

\section{Availability of data and materials}

Nearly all data relevant to the study is included in this article. Other data are available upon reasonable request, if ethic committees involved grant permission to do so.

\section{Ethics approval and consent to participate}

The project was approved by the Institutional Review Board of the Coordinating Center (Vall d'Hebron Research Institute, Barcelona), and by review boards of each institution recruiting participants.

\section{Consent for publication}

Not applicable.

\section{Competing interests}

The authors declare that they have no competing interests.

\section{Author details}

${ }^{1}$ MRC Centre for Neuromuscular Diseases, UCL Institute of Neurology, National Hospital, London, UK. ${ }^{2}$ Faculty of Sport Sciences, Universidad Europea de Madrid, Madrid, Spain. ${ }^{3}$ Instituto de Investigación Hospital, 12 de Octubre (imas12), Madrid, Spain. ${ }^{4}$ Universidad Pablo de Olavide, Seville, Spain. ${ }^{5}$ Dept. of Conegliano-Pieve Di Soligo, IRCCS Medea Scientific Insitute, Bosisio Parini, Italy. ${ }^{6}$ Neurology and Neuromuscular Diseases Unit, Department of Clinical and Experimental Medicine, University of Messina, Messina, Italy. ${ }^{7}$ Department of Neurology, Donders Institute for Brain, Cognition and Behaviour, Radboud University Medical Center, Nijmegen, The Netherlands. ${ }^{8}$ Nord/Est/lle de France Neuromuscular Reference Center, Neurology Department, Raymond-Poincaré Teaching Hospital, Garches. AP-HP. INSERM U1179, END-ICAP, Paris Saclay University, Paris, France. ${ }^{9}$ Pathology Deparment, Alvaro Cunqueiro Hospital, Vigo, Spain. ${ }^{10}$ Rare Diseases and Pediatric Medicine Research Group, Galicia Sur Health Research Institute (IIS Galicia Sur), SERGASUVIGO, Vigo, Spain. ${ }^{11}$ Neurology and Neuromuscular Diseases Unit, Department of Clinical and Experimental Medicine, University of Pisa, Pisa, Italy. ${ }^{12}$ Department of Neurology, Heimer Institute for Muscle Research, University Hospital Bochum, Bochum, Germany. ${ }^{13}$ Peripheral Nervous System and Muscle Department, CHU Nice, Université Côte D'Azur, Institute for Research On Cancer and Aging of Nice (IRCAN), INSERM U1081, CNRS UMR 7284, Faculty of Medicine, Université Côte D'Azur (UCA), Nice, France. ${ }^{14}$ Copenhagen Neuromuscular Center, Section 6921, Rigshospitalet, University of Copenhagen, 2100 Copenhagen, Denmark. ${ }^{15}$ Istanbul Faculty of Medicine, Istanbul University, Istanbul, Turkey. ${ }^{16}$ Department of Neurology, Medical University of Warsaw, Warsaw, Poland. ${ }^{17}$ Association for Glycogen Storage Disease (UK), Bristol, UK. ${ }^{18}$ Biomedical Network Research Centre on Rare Diseases (CIBERER), Instituto de Salud Carlos III, and Research Group on Neuromuscular and Mitochondrial Diseases, Vall d'Hebron Research Institute, Universitat Autònoma de Barcelona, Barcelona, Catalonia, Spain.

Received: 24 April 2020 Accepted: 25 September 2020

Published online: 24 November 2020

\footnotetext{
References

1. Augustine EF, Adams HR, Mink JW. Clinical trials in rare disease: challenges and opportunities. J Child Neurol. 2013;28:1142-50.

2. Conwit RA, Bhanushali MJ, Porter JD, et al. Adding more muscle and nerve to clinical trials. Muscle Nerve. 2011;44:695-702.

3. Stoller JK. The challenge of rare diseases. Chest. 2018;153:1309-14.
} 
4. Orphanet_Report_Series. Rare Diseases Registries in Europe2018 May 2018.

5. EUROMAC registry of patients with MCArdle disease and other rare glycogenolytic disorders with exercise intolerance. www.euromacregistry .eu. Accessed 06/05/2018.

6. Euromac Registry introduction. YouTube 2013. https://www.youtu be.com/watch?v=NXvmRGLcly8\&list=PLECPX8EZXgfMflBqX4hWLYC4 n_4bieuwV.

7. Pinós T, Andreu AL, Bruno C, Hadjigeorgiou GM, Haller RG, Laforêt P, Lucía A, Martín MA, Martinuzzi A, Navarro C, Oflazer P, Pouget J, Quinlivan R, Sacconi S, Scalco R, Toscano A, Vissing J, Vorgerd M, Wakelin A, Martí R, EUROMAC Consortium. Creation and implementation of a European registry for patients with McArdle disease and other muscle glycogenoses (EUROMAC Registry). Orphanet J Rare Dis. 2020;15:187. https://doi. org/10.1186/s13023-020-01455-z.

8. AGSD-UK. Association for Glycogen Storage Disease (UK). https://www. agsd.org.uk. Accessed 20/06/2016.

9. EUROMAC teaching course: diagnosis and management of McArdle disease and rare muscle glycogenoses. https://www.euromacregistry .eu/portal $1 /$ content.asp?contentid $=1221 \& \mathrm{c}=$ EUROMAC\%20TEACHING \%20COURSE. Accessed 05/05/2018.

10. Scalco R, Vissing C, Godfrey R, Chatfield S, Løkken N, Madsen K, Pattni J, Michalak Z, Sewry C, Fox Z, McKenna G, Samandouras G, Holton J, Howell J, Haller R, Vissing J, Quinlivan R. Sodium valproate for McArdle disease (glycogen storage disease type V - GSDV). Neuromuscul Disord. 2015;25:S220-1.

11. Scalco RS. Translational research studies in exercise-related muscle disorders. PhD thesis. UCL, London: University College London, 2018.

12. ClinicalTrials.gov. Fat and sugar metabolism during exercise in patients with metabolic myopathy. https://clinicaltrials.gov/ct2/show/NCT02 635269? cond=beta+enolase\&rank=1. Accessed 08/10/2018.

13. Laforêt $P$, Inoue M, Goillot E, Lefeuvre C, Cagin U, Streichenberger N, Leonard-Louis S, Brochier G, Madelaine A, Labasse C, Hedberg-Oldfors C, Krag T, Jauze L, Fabregue J, Labrune P, Milisenda J, Nadaj-Pakleza A, Sacconi S, Mingozzi F, Ronzitti G, Petit F, Schoser B, Oldfors A, Vissing J, Romero NB, Nichino I, Malfatti E. Deep morphological analysis of muscle biopsies from type III glycogenesis (GSDIII), debranching enzyme deficiency, revealed stereotyped vacuolar myopathy and autophagy impairment. Acta Neuropathol Commun. 2019;7(1):167. https://doi.org/10.1186/s4047 8-019-0815-2.

14. Madsen KL, Laforêt P, Buch AE, Stemmerik MG, Ottolenghi C, Hatem SN, Raaschou-Pedersen DT, Poulsen NS, Atencio M, Luton MP, Ceccaldi A, Haller RG, Quinlivan R, Mochel F, Vissing J. No effect of triheptanoin on exercise performance in McArdle disease. Ann Clin Transl Neurol. 2019;6(10):1949-60.

15. Vissing J, Akman HO, Aasly J, Kahler SG, Bacino CA, DiMauro S, Haller RG. Level of residual enzyme activity modulates the phenotype in phosphoglycerate kinase deficiency. Neurology. 2018;91(11):e1077-82.

16. Stemmerik MG, Madsen KL, Laforêt P, Buch AE, Vissing J. Muscle glycogen synthesis and breakdown are both impaired in glycogenin-1 deficiency. Neurology. 2017;89(24):2491-4.

17. Voermans NC, Preisler N, Madsen KL, Janssen MC, Kusters B, Abu Bakar $\mathrm{N}$, Conte F, Lamberti VM, Nusman F, van Engelen BG, van Scherpenzeel M, Vissing J, Lefeber DJ. PGM1 deficiency: substrate use during exercise and effect of treatment with galactose. Neuromuscul Disord. 2017:27(4):370-6.

18. Krag TO, Pinós T, Nielsen TL, Duran J, García-Rocha M, Andreu AL, Vissing J. Differential glucose metabolism in mice and humans affected by McArdle disease. Am J Physiol Reg Int Comp. 2016;311(2):R307-14.

19. Krag TO, Pinós T, Nielsen TL, Brull A, Andreu AL, Vissing J. Differential muscle involvement in mice and humans affected by McArdle disease. J Neuropathol Exp Neurol. 2016;75(5):441-54.

20. Ørngreen MC, Jeppesen TD, Taivassalo T, Hauerslev S, Preisler N, Heinecke K, Haller RG, Vissing J, van Hall G. Lactate and energy metabolism during exercise in patients with blocked glycogenolysis (McArdle disease). J Clin Endocrinol Metab. 2015;100(8):E1096-104.

21. Preisler N, Laforet P, Madsen KL, Prahm KP, Hedermann G, Vissing CR, Galbo H, Vissing J. Skeletal muscle metabolism is impaired during exercise in glycogen storage disease type III. Neurology. 2015;84(17):1767-71.

22. Scalco RS, Morrow JM, Booth S, Chatfield S, Godfrey R, Quinlivan R. Misdiagnosis is an important factor for diagnostic delay in McArdle disease. Neuromuscul Disord. 2017:27:852-5.

23. Quinlivan R, Buckley J, James M, Twist A, Ball S, Duno M, Vissing J, Bruno C, Cassandrini D, Roberts M, Winer J, Rose M, Sewry C. McArdle disease: a clinical review. J Neurol Neurosurg Psych. 2010;81:1182-8.

24. Santalla A, Nogales-Gadea G, Encinar AB, Vieitez I, González-Quintana A, Serrano-Lorenzo P, Consuegra IG, Asensio S, Ballester-Lopez A, PintosMorell G, Coll-Cantí J, Pareja-Galeano H, Díez-Bermejo J, Pérez M, Andreu AL, Pinós T, Arenas J, Martín MA, Lucia A. Genotypic and phenotypic features of all Spanish patients with McArdle disease: a 2016 update. BMC Genomics. 2017;18:819.

25. Michelson J. My diagnostic odyssey — a call to expand access to genomic testing for the next generation. The Hastings Center Report. 2018;48:S32-4

26. Nadaj-Pakleza AA, Vincitorio CM, Laforêt P, Eymard B, Dion E, Teijeira S, Vietez I, Jeanpierre M, Navarro C, Stojkovic T. Permanent muscle weakness in McArdle disease. Muscle Nerve. 2009;40(3):350-7.

27. Prakalapakorn SG, Proia AD, Yanovitch TL, DeArmey S, Mendelsohn NJ, Aleck KA, Kishnani PS. Ocular and histologic findings in a series of children with infantile Pompe disease treated with enzyme replacement therapy. J Pediatr Ophthal Strab. 2014;51 (6):355-62.

28. Wens SC, van Gelder CM, Kruiijshaar ME, de Vries JM, van der Beek NA, Reuser AJ, van Doorn PA, van der Ploeg AT, Brusse E. Phenotypical variation within 22 families with Pompe disease. Orphanet J Rare Dis. 2013;8:182. https://doi.org/10.1186/1750-1172-8-182.

29. Taylor PN, Albrecht D, Scholz A, Gutierrez-Buey G, Lazarus JH, Dayan CM, Okosieme OE, et al. Global epidemiology of hyperthyroidism and hypothyroidism. Nature Rev Endocrinol. 2018;14:301-16.

30. Mahroo OA, Khan KN, Wright G, Ockrim Z, Scalco RS, Robson AG, Tufail A, Michaelides M, Quinlivan R, Webster AR. Retinopathy associated with bi-allelic mutations in PYGM (McArdle disease). Ophthalmology. 2019;126(2):320-2.

\section{Publisher's Note}

Springer Nature remains neutral with regard to jurisdictional claims in published maps and institutional affiliations.

Ready to submit your research? Choose BMC and benefit from:

- fast, convenient online submission

- thorough peer review by experienced researchers in your field

- rapid publication on acceptance

- support for research data, including large and complex data types

- gold Open Access which fosters wider collaboration and increased citations

- maximum visibility for your research: over 100M website views per year

At BMC, research is always in progress.

Learn more biomedcentral.com/submissions 